\title{
Alteração da cobertura vegetal na Sub-Bacia do Rio Espinharas de 2000 a 2010
}

\author{
Rosangela M. P. Silva ${ }^{1}$, Joedla R. Lima ${ }^{2}$ \& Izaque F. C. de Mendonça ${ }^{3}$
}

${ }^{1}$ FIP. Patos, PB. E-mail: profarosangelapereira@hotmail.com (Autor correspondente)

${ }^{2}$ PPGCE/UFCG. Patos, PB. E-mail: joedlalima@yahoo.com.br

${ }^{3}$ UAEF/UFCG. Patos, PB. E-mail: izaquecandeia@gmail.com

\section{Palavras-chave:}

semiárido nordestino

caatinga

índice de vegetação por diferença

normalizada

sistema de processamento de

informações georreferenciadas

\section{R E S U M O}

No semiárido nordestino o aumento da área desflorestada e não recuperada da Caatinga degradada fragiliza seus solos e seu equilíbrio hidrológico. Este trabalho teve como objetivo mapear a alteração da cobertura vegetal na Sub-Bacia do Rio Espinharas no período 2000-2010. Os dados das imagens do sensor Thematic Mapper do satélite Landsat-5 foram processados no ambiente Spring. Para avaliação da cobertura vegetal utilizou-se o índice de vegetação por diferença normalizada. $65 \%$ da área apresentam alto grau de antropismo, vegetação rala e solos expostos. A imagem diferença foi analisada considerando-se os valores da média de distribuição dos níveis de cinza na imagem $(\mu)$ e do desvio padrão $(\sigma)$, segundo os limiares $[0, \mu-\sigma],[\mu-\sigma, \mu+\sigma]$ e $[\mu+\sigma, 254]$ relacionando-os às classes: desmatamento/redução, não mudança e áreas de regeneração/incremento da vegetação. Os resultados mostram que $80 \%$ da área se mantêm inalterados; em $12,6 \%$ da área ocorreu redução da cobertura vegetal pelas práticas de corte raso para obtenção de lenha para uso doméstico ou comercial e preparo da área para a agricultura e em $7,4 \%$ da área registrou-se incremento possivelmente favorecido pelo cultivo de pastagens irrigadas e não irrigadas em solos de aluvião.

\section{Key words:}

semiarid northeast

'Caatinga'

normalized difference vegetation

index

georeferenced information

processing system

\section{Alteration in the vegetation cover in Sub-Basin of River Espinharas from 2000 to 2010}

\begin{abstract}
A B S T R A C T
In the semiarid northeast, the increase in the area of deforestation and non-reclaimed 'Caatinga' sites already degraded weaken its soils and hydrological balance. This study aimed to map the alteration in the vegetation cover along the Espinharas River sub-basin area during the period 2000-2010. The image data collected from the thematic mapper sensor of the satellite Landsat- 5 were processed with the aid of computational systems Spring. In order to evaluate the vegetation cover, the normalized difference vegetation index was used. Sixty five percent of the area presented high level of anthropogenic disturbance, sparse vegetation and exposed soils. The difference in image, whose values were analysed taking into account the values of the average distribution of gray levels in the image $(\mu)$ standard deviation ( $\sigma$ ) according to the thresholds $[0, \mu-\sigma],[\mu-\sigma, \mu+\sigma]$ e $[\mu+\sigma, 254]$, related to the following classifications: deforestation/reduction of vegetation cover, no change and areas of regeneration/vegetation growth. The results showed that $80 \%$ of the area remains unchanged, reduction of vegetation cover occurred in $12.6 \%$ of the area due to the practice of clear cutting of vegetation in order to obtain firewood for domestic or commercial use and also area preparation for agriculture purposes; some increment was observed in $7.4 \%$ of the area possibly due to cultivation of irrigated and non-irrigated pastures in alluvial soils.
\end{abstract}

\section{INTRODUÇÃo}

Preservar a cobertura vegetal é condição fundamental para a conservação dos recursos hídricos uma vez que a vegetação tem importante função na proteção e na manutenção de nascentes e cursos d'água. Sua retirada descaracteriza os ambientes originais dos rios e interfere no balanço hídrico das bacias hidrográficas.

A cobertura vegetal, notadamente das matas ciliares, ao longo dos ambientes ribeirinhos intermitentes, na região semiárida, tem significativa relevância na proteção dos ambientes aquáticos e na regulação e manutenção da diversidade biológica bem como é fator importante na estabilidade dos solos e na manutenção dos sistemas hidrológicos (Lacerda et al., 2007).

A "Região Semiárida", área em que predomina o bioma Caatinga, vem sendo exposta a um processo de degradação intensa pelo avanço da pecuária, iniciada no século XVII (Nogueira \& Simões, 2009; Alves et al., 2008) situação agravada ao longo dos anos pelo uso incorreto das suas terras, por meio da exploração predatória, desmatamentos e queimadas (Brasileiro, 2009; Pessoa et al., 2008) ameaçando a sobrevivência de muitas espécies vegetais e animais, tanto quanto a qualidade e a quantidade dos recursos hídricos. 
Nos estados da Paraíba e do Rio Grande do Norte, 92 e 95\%, respectivamente, das suas áreas territoriais correspondem ao bioma Caatinga (Cavalcante, 2009) situando-se entre as mais afetadas pelo processo de desertificação (Alves et al., 2008).

A Sub-bacia do Rio Espinharas integra a Bacia Hidrográfica Piranhas-Açu, importante sistema da Região Semiárida nordestina e a Região Hidrográfica Atlântico Nordeste Oriental. É tipicamente de regime intermitente, encravada no domínio do bioma Caatinga e do clima semiárido, caracterizado pela elevada variabilidade temporal e espacial das precipitações (Medeiros, 2003), com longos períodos de estiagem, médias pluviométricas em torno de $700 \mathrm{~mm}$ anuais, evapotranspiração entre $2000 \mathrm{e}$ $2500 \mathrm{~mm}$ anuais, umidade relativa do ar variando de 55 a $75 \%$ (Paraíba, 2006) índice de aridez entre 0,20 e 0,50 e alto nível de risco de desertificação (Paraíba, 2011).

A área estudada apresenta alto grau de antropismo carcterizando em $2010,66 \%$ da sub-bacia fato que merece atenção dos órgãos gestores, pois a devastação da cobertura vegetal expõe os solos a uma degradação que dificulta a reconstituição desta vegetação que, por sua vez, compromete as condições hídricas da sub-Bacia hidrográfica (Alves, 2007; Franco et al., 2007).

O índice de vegetação por diferença normalizada (NDVI) é um dos índices mais utilizados para estimar a biomassa com o uso de imagens orbitais sendo uma variável significativamente afetada pelo regime de precipitação pluviométrica da região em análise (Aquino \& Oliveira, 2012; Firmino et al., 2009; Albuquerque et al., 2007).

A pesquisa teve como objetivo mapear a alteração da cobertura vegetal na Sub-bacia do Rio Espinharas, no período 2000-2010. Para isto realizou-se a caracterização das condições hidrogeográficas da Sub-bacia do Rio Espinharas; o cálculo do índice de vegetação por diferença normalizada (NDVI) na área da sub-bacia, nos anos 2000 e 2010, através do processamento de imagens orbitais; a avaliação da alteração da cobertura vegetal na área, no período 2000-2010, através da subtração entre as imagens NDVI e a identificação de áreas de mudança negativa do ponto de vista da alteração da cobertura vegetal na área estudada e as prováveis causas.

\section{MATERIAL E MÉtodos}

A área da Sub-bacia do Rio Espinharas compreende uma superfície de cerca de $3.301,03 \mathrm{~km}^{2}$ nos estados da Paraíba e do Rio Grande do Norte, situada entre os paralelos de $-6^{\circ} 25^{\prime} 50,9^{\prime \prime}$ e - $7^{\circ} 21^{\prime} 48,6^{\prime \prime}$ e os meridianos de -37 $33^{\prime} 09,7^{\prime \prime}$ e - $36^{\circ} 43^{\prime} 52,3^{\prime \prime}$.

O Rio Espinharas se forma pela confluência do Rio da Cruz, que nasce no município de Imaculada, PB, como Rio da Farinha, originado no município de Salgadinho, PB, na área urbana do município de Patos, PB.

Na divisa dos estados da Paraíba e do Rio Grande do Norte o Rio Espinharas deságua no Rio Piranhas, no município de Serra Negra do Norte, RN, nos limites deste município com o também município potiguar de Jardim de Piranhas e o município paraibano de São Bento.
A caracterização hidrogeográfica da Sub-bacia do Rio Espinharas resultou do resgate teórico junto às produções bibliográficas, trabalhos acadêmicos, publicações de órgãos públicos e instituições científicas, constituindo um embasamento informacional e argumentativo sobre a temática e a área de estudo, e subsídios para as análises temporais das imagens de satélites, bem como para explicação dos aspectos observados no campo.

As imagens multiespectrais do satélite Landsat 5-TM, especificadas na Tabela 1 , foram disponibilizadas pela divisão de geração de imagens (DGI), do Instituto Nacional de Pesquisas Espaciais (INPE), com resolução espacial de $30 \mathrm{~m}$, sendo estas extraídas para uma pasta e importadas para o software SPRING (Camara et al., 1996) versão 5.1.7, onde foi criado o Banco de Dados "Sub_Bacia_Espinharas", contendo os Projetos a seguir: "Espinharas_2000_NDVI", "Espinharas_2010_NDVI" e "Espinharas_SRTM".

Tabela 1. Identificação das imagens orbitais com cobertura para a área de estudo

\begin{tabular}{ccccc}
\hline Satélite & Sensor & Órbita & Ponto & Data \\
LANDSAT 5 & TM & 216 & 64 & $10 / 10 / 2000$ \\
LANDSAT 5 & TM & 216 & 65 & $10 / 10 / 2000$ \\
& & & & $06 / 10 / 2010$ \\
LANDSAT 5 & TM & 215 & 65 & $\begin{array}{l}04 / 11 / 2000 \\
15 / 10 / 2010\end{array}$ \\
\hline
\end{tabular}

Fonte: Catálogo de imagens do INPE

Em seguida foram criados os planos de informação (PI) pertencentes às categorias a) "Imagem", para onde foram importadas as imagens ${ }^{*}$.spg, obtidas pela conversão das imagens ${ }^{*}$.tiff no módulo Impima do SPRING; b) "MNT", para as imagens IVDNs, Diferença, Hipsometria, Declividades, Drenagem_ACM (grade de fluxos acumulados), Drenagem LDD (grade de direções de fluxo) e suas respectivas grades numéricas, as duas primeiras geradas a partir das imagens Landsat 5 e as demais da imagem SRTM e c) "Temático", com o polígono correspondente à delimitação da área da sub-bacia estudada, máscara utilizada para os recortes das imagens ${ }^{*}$.spg, pontos e polígonos das áreas amostrais, arquivos no formato *shp; Hipsometria, Declividades, NDVI_2000, NDVI_2010 e Alteração da cobertura vegetal, com suas respectivas classes temáticas, arquivos matriciais, sendo os mapas editados a partir das imagens Landsat-5 e SRTM.

A delimitação da área da sub-bacia foi realizada a partir de pontos georreferenciados, extraídos do mapa disponível na página da Agência Executiva de Gestão das Águas do Estado da Paraíba (AESA-PB), no link "Geoportalaesa", ativando-se o plano de informação "sub-bacias" e no mapa disponível na página do Instituto de Desenvolvimento Sustentável e Meio Ambiente do Estado do Rio Grande do Norte (IDEMA), no link "SiggaWeb", ativando-se as camadas "Meio físico - Altimetria - classes altimétricas 50 m" e "Hidrografia Drenagens", identificando-se suas respectivas coordenadas E e N (X e Y), adotando-se o Datum horizontal WGS-84 e o Sistema de Projeção Universal Transversa de Mercator (UTM), 
Zona 24 S, transferidos para o software MapSource 6.12 e salvos em arquivo do tipo ${ }^{*}$.dxf.

$\mathrm{O}$ arquivo foi importado para o software Spring e gerado o polígono constituindo a máscara da área da Sub-bacia do Rio Espinharas, que foi sobreposta ao mosaico das imagens do Landsat5-TM (ThematicMapper) e SRTM (Shuttle Radar Topography Mission), previamente georreferenciadas, para o recorte da área de investigação.

A partir das reflectâncias das bandas 3 e 4 do Landsat 5 foi obtido o índice de vegetação por diferença normalizada (NDVI) utilizado para averiguar o comportamento das mudanças temporal e espacial da vegetação; para isto foram aplicadas a opção "operações aritméticas" e a Eq. 1 nas bandas 3 e 4 da imagem da área de estudo (Tabela 2):

$$
\mathrm{NDVI}=\text { Ganho } \times\left(\frac{\mathrm{A}-\mathrm{B}}{\mathrm{A}+\mathrm{B}}\right)+\text { Offset }
$$

Foram aplicados os valores de Ganho: 127 e Offset: 128, gerando as imagens NDVI_2000 e NDVI_2010 (Tabela 3), com valores dos níveis digitais de cinza da imagem escalonados de 0 a 255.

Tabela 2. Parâmetros estatísticos das imagens orbitais

\begin{tabular}{cccc}
\hline Ano - Banda & Média $(\boldsymbol{\mu})$ & Desvio padrão $(\boldsymbol{\sigma})$ & Variância $\left(\boldsymbol{\sigma}^{2}\right)$ \\
$2000-3$ & 60,963600 & 18,126817 & 328,581511 \\
$2000-4$ & 70,362159 & 16,480857 & 217,618638 \\
$2010-3$ & 59,966508 & 17,632781 & 310,914977 \\
$2010-4$ & 70,953244 & 17,750281 & 315,072489 \\
\hline
\end{tabular}

Tabela 3. Parâmetros estatísticos das imagens de índice de vegetação por diferença normalizada (NDVI)

\begin{tabular}{cccc}
\hline Ano & Média $(\boldsymbol{\mu})$ & Desvio padrão $(\boldsymbol{\sigma})$ & Variância $\left(\boldsymbol{\sigma}^{2}\right)$ \\
2000 & 137,422426 & 10,00463 & 100,092620 \\
2010 & 138,494048 & 7,86465 & 61,852726 \\
\hline
\end{tabular}

Para obtenção dos valores normalizados entre -1 e 1, expressando os valores do NDVI original, aplicou-se a Eq. 2 (Santos et al., 2010):

$$
\mathrm{NDVI}_{\text {original }}=\mathrm{NDVI}_{\text {processado }}-\frac{\text { Offset }}{\text { Ganho }}
$$

A fim de auxiliar na análise dos resultados aplicou-se a cada imagem NDVI à operação "Geração de MNT" para obtenção da grade com os valores de NDVI processados e, em seguida, a criação de classes temáticas com base em intervalos de valores de reflectância do NDVI e aplicação da operação "Fatiamento" para geração das imagens temáticas, com intervalos de valores definidos associados a uma gradação de cores. Valores menores que 0 correspondem aos corpos d’água e nuvens; valores distribuídos entre 0 e 1 expressam uma gradação de áreas de solo exposto e/ou de forte antropismo até áreas vegetadas, de menos densa a mais densa cobertura vegetal, predominando valores entre 0 e 0,1 .

A interpretação visual das imagens NDVI's para identificação dos tipos de cobertura vegetal na área em estudo foi realizada com base na observação de variáveis como a tonalidade/cor e a textura nas imagens resultantes da composição multiespectral ajustada, validada através da inspeção em campo em pontos selecionados previamente dentro dos limites de nove áreas amostrais.

Cada uma das áreas amostrais foi definida com dimensão de 10 pixels x 10 pixels, ou seja, 100 pixels ou $90.000 \mathrm{~m}^{2}$, com representação o mais homogênea possível e significativa de diferentes tonalidades/cores e texturas, distribuídas aleatoriamente na área da Sub-bacia do Rio Espinharas.

A cobertura vegetal foi classificada em Caatinga arbustiva arbórea aberta (Tipo T2); Caatinga arbustiva arbórea fechada (Tipo T3) e Caatinga arbórea fechada (Tipo T4), considerandose a classificação adotada em Projeto desenvolvido pelo Programa das Nações Unidas para a Agricultura e a Alimentação (FAO), em conjunto com o Programa das Nações Unidas para o Meio Ambiente - PNUD (SUDEMA, 2004).

Para avaliação da alteração da cobertura vegetal na área da Sub-bacia do Rio Espinharas, no período 2000-2010, foi realizada a subtração entre as imagens NDVI _2010 e NDVI_2000, aplicando-se a opção "operações aritméticas" e a Eq. 3:

$$
\mathrm{C}=\operatorname{Ganho} \times(\mathrm{A}-\mathrm{B})+\text { Offset }
$$

em que:

$\mathrm{C}$ - imagem diferença

A e B - imagens NDVI correspondentes aos anos 2010 e 2000, com valores de ganho e offset 1 e 127, respectivamente, evitando-se, assim, a saturação dos resultados para valores acima de 255

A imagem diferença (Tabela 4) representa o resultado algébrico da subtração entre as imagens NDVI_2010 e NDVI_2000, expressando o aumento ou a redução da cobertura vegetal no intervalo de tempo de dez anos.

Tabela 4. Parâmetros estatísticos da imagem diferença 2010-2000

\begin{tabular}{ccccc}
\hline Mínima & Máxima & $\begin{array}{c}\text { Média } \\
(\boldsymbol{\mu})\end{array}$ & $\begin{array}{c}\text { Desvio } \\
\text { padrão }(\boldsymbol{\sigma})\end{array}$ & $\begin{array}{c}\text { Variância } \\
\left(\boldsymbol{\sigma}^{2}\right)\end{array}$ \\
0 & 254 & 128,071554 & 10,160151 & 103,228659 \\
\hline
\end{tabular}

A imagem diferença foi classificada levando-se em consideração os valores da média $(\mu)$ de distribuição dos níveis de cinza na imagem e do desvio padrão $(\sigma)$, segundo os limiares e classes temáticas: $[0, \mu-\sigma]=$ desmatamento/redução da cobertura vegetal $[\mu-\sigma, \mu+\sigma]=$ sem alteração e $[\mu+\sigma, 254]=$ áreas de regeneração/incremento de vegetação.

Os valores originais da subtração entre os valores do NDVI referentes aos anos de 2010 e 2000, entre -127 e 127 foram obtidos através da Eq. 4 adaptada da Eq. 3:

$$
\text { Dif. Original }=\text { Dif.Processada }-\frac{\text { Offset }}{\text { Ganho }}
$$


Tabela 5. Sub-Bacia do Rio Espinharas: Municípios

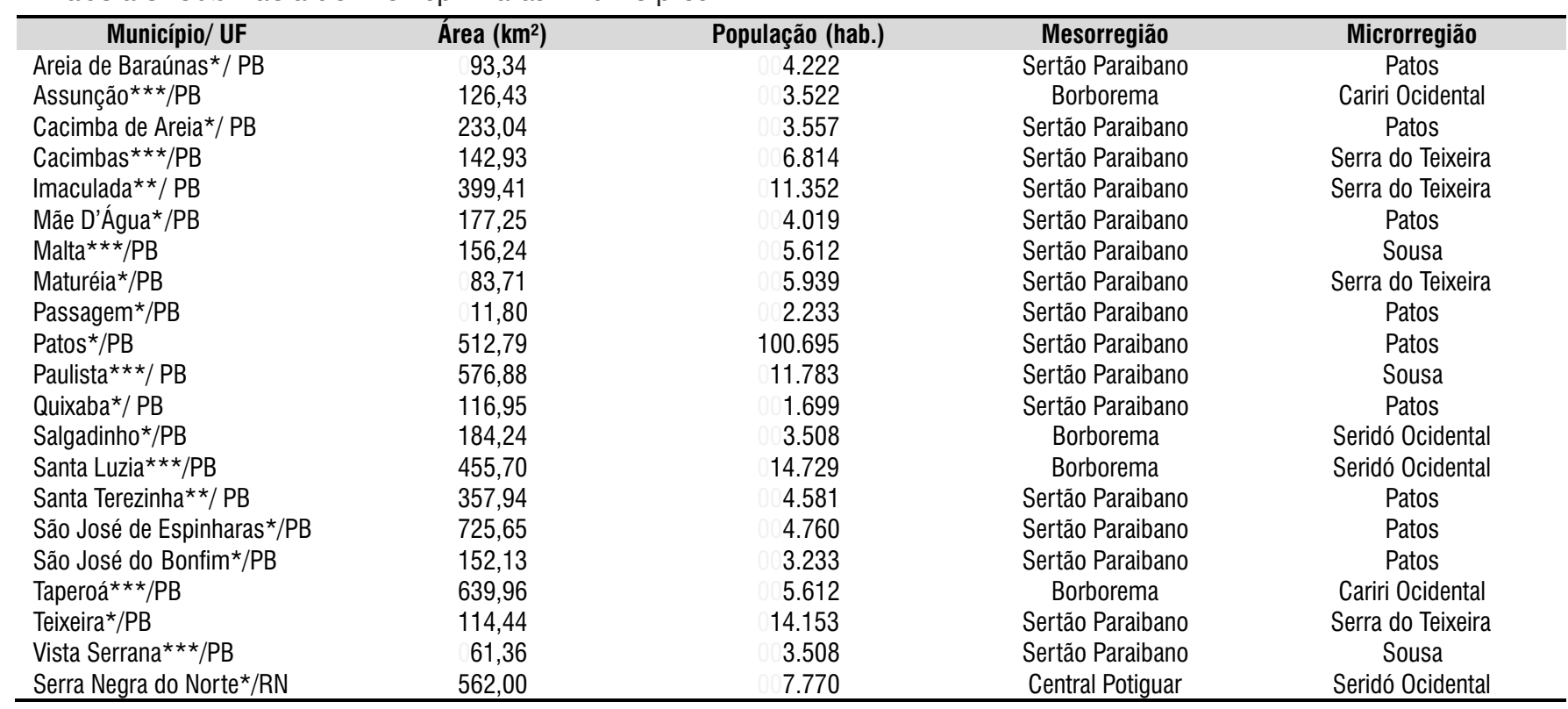

* Municípios (12) com área territorial totalmente inserida na área de drenagem da Sub-bacia do Rio Espinharas; **Municípios (02) com parcela significativa do seu território na área de drenagem da Sub-bacia do Rio Espinharas; ${ }^{* \star \star M u n i c i ́ p i o s ~(07) ~ c o m ~ p e q u e n a ~ p a r c e l a ~ d o ~ s e u ~ t e r r i t o ́ r i o ~ i n s e r i d a ~ n a ~ a ́ r e a ~ d e ~ d r e n a g e m ~ d a ~ s u b-b a c i a ~ e m ~ e s t u d o ~ e ~ q u e ~ f a z e m ~ p a r t e ~ d e ~ o u t r a s ~ s u b-b a c i a s . ~}$ Fonte: AESA (2010a); IBGE (2010)

\section{Resultados e Discussão}

A área de drenagem da Sub-bacia do Rio Espinharas se estende, completa ou parcialmente, por vinte e um municípios, sendo vinte no estado da Paraíba e um no estado do Rio Grande do Norte (Tabela 5). Está inserida nas mesorregiões do Sertão Paraibano e Borborema, abrangendo parte das microrregiões de Patos, Serra do Teixeira, Seridó Ocidental, Cariri Ocidental e Sousa, na Paraíba (AESA, 2010a) e no Rio Grande do Norte ocupa parte da mesorregião Central Potiguar e microrregião do Seridó Ocidental (IBGE, 2010).

Todos os seus cursos d'água têm regime de escoamento intermitente e o padrão de drenagem predominante é o dendrítico (Figura 1).

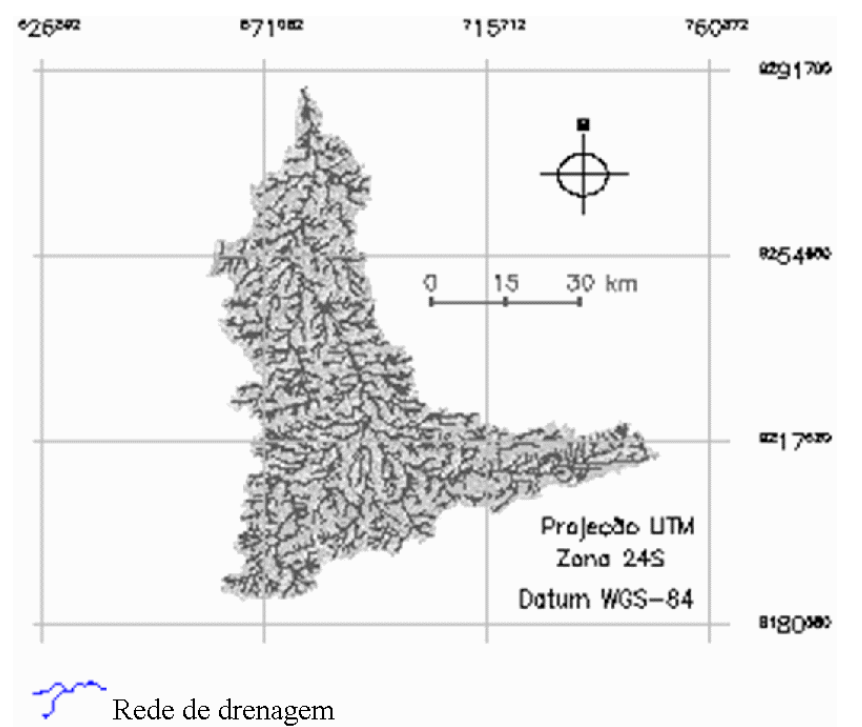

Figura 1. Sub-bacia do Rio Espinharas: Rede de drenagem
A Sub-bacia do Rio Espinharas é de fundamental importância para o abastecimento humano e o desenvolvimento das atividades produtivas nos municípios de sua área de abrangência, destacando-se o município de Patos como o mais representativo em termos populacionais e econômicos (Paraíba, 2006).

A Sub-bacia do Rio Espinharas está inserida na Depressão Sertaneja Setentrional, paisagem típica do semiárido nordestino, uma extensa planície com elevações residuais disseminadas na paisagem (Ferreira et al., 2009). As altitudes variam de 127 a $1.186 \mathrm{~m}$.

A Tabela 6 apresenta as classes de declividades e a porcentagem da área da sub-bacia ocupada por cada classe, segundo a classificação apresentada por Ramalho Filho \& Beek (1995) demonstrando predominância de relevo suave ondulado em $40 \%$ da área.

Conforme a classificação de Köppen ocorrem, na área estudada, os climas classificados como Bsh estendendo-se pela porção sudeste da sub-bacia - clima quente e seco, com chuvas de verão, média pluviométrica anual em torno dos 500 $\mathrm{mm}$ e temperatura média anual de $26^{\circ} \mathrm{C}$ e Aw', alastrando-se pela porção centro ocidental da sub-bacia - clima quente e semiúmido com chuvas de verão-outono, média pluviométrica anual em torno de $800 \mathrm{~mm}$ e temperatura média anual de 27

Tabela 6. Classes de declividade e percentual da área da sub-bacia do Rio Espinharas para cada classe

\begin{tabular}{lc}
\hline Classes de declividades & \% da Área \\
0 a 2\% - Plano & 17,6 \\
a 5\% - Suave ondulado & 40,0 \\
5 a 10\% - Moderadamente ondulado & 16,9 \\
10 a 20\% - Ondulado & 11,7 \\
20 a 40\% - Forte ondulado & 10,6 \\
> 40\% - Montanhoso e escarpado & 3,2 \\
\hline
\end{tabular}


${ }^{\circ} \mathrm{C}$ - sendo que este último domina todo o pediplano sertanejo (AESA, 2010a; Paraíba, 2011).

A taxa de evapotranspiração varia entre 2000 e 2500 mm anuais, com a umidade relativa do ar variando de 55 a $75 \%$ (Paraíba, 2006) e índice de aridez da área pela qual se estende a sub-bacia estudada entre 0,20 e 0,50 (Paraíba, 2011).

Segundo a AESA (2010b), a área da Sub-bacia do Rio Espinharas tem seu período chuvoso compreendido entre os meses de fevereiro a maio, com precipitações médias variando entre 400 e $800 \mathrm{~mm}$ anuais, representativas da atuação dos sistemas da Zona de Convergência Intertropical, sendo os Vórtices Ciclônicos em Ar Superior responsáveis por aproximadamente $80 \%$ do total precipitado.

As chuvas de pré-estação ocorrem durante o mês de janeiro, em forma de pancada, relevantes para a recuperação hídrica dos corpos d'água. A partir do mês de setembro os últimos meses do ano se configuram no período típico de estiagem (Tabela 7) (AESA, 2010b).

No geral, os solos na área da Sub-bacia do Rio Espinharas são pouco profundos, pedregosos, de origem cristalina e muito susceptíveis à erosão, com predominância dos solos: a) Brunos não-cálcicos e Litólicos eutróficos (Classes 3: Luvissolos, Argissolos, Alissolos e Nitossolos e 8: Neossolos, respectivamente); b) Podzólicos vermelho amarelo eutrófico (Classe 3); c) Litólicos distróficos, Regossolos e solos aluviais (Classe 8); e d) Latossolos (Classes 1: Latossolo amarelo e vermelho amarelo e 2: Latossolo vermelho escuro) (AESA, 2010a) conforme classificação apresentada por Melo Filho \& Souza (2006).

$\mathrm{Na}$ maior parte da área estudada predominam a Caatinga arbustiva arbórea aberta (T2) constituída por uma vegetação rala com alguns indivíduos arbóreos, com altura média de $3 \mathrm{~m}$ e a presença de vegetação herbácea e cactácea, encontrando-se com alto grau de antropismo nas áreas de relevo plano.

Em áreas classificadas como Caatinga arbustiva arbórea aberta (T2), constatou-se predominância da Herissantia crispa (L.) Briz. (malva-branca) e da Pavonia cancellata (L.) Cav. (malva-rasteira), compondo o estrato herbáceo; cactáceas,

Tabela 7. Precipitação média histórica e precipitações mensais observadas na área da Sub-bacia do Rio Espinharas nos anos 2000 e 2010

\begin{tabular}{cccc}
\hline \multirow{2}{*}{ Meses } & Precipitação média & \multicolumn{2}{c}{ Precipitação observada (mm) } \\
\cline { 3 - 4 } histórica (mm) & $\mathbf{2 0 0 0}$ & $\mathbf{2 0 1 0}$ \\
Jan. & 66,3 & 93,4 & 110,1 \\
Fev. & 134,1 & 149,9 & 47,1 \\
Mar. & 201,4 & 137,0 & 97,5 \\
Abr. & 177,9 & 123,8 & 122,5 \\
Mai. & 60,4 & 20,1 & 19,0 \\
Jun. & 27,0 & 8,0 & 63,9 \\
Jul. & 14,6 & 20,6 & 0,8 \\
Ago. & 3,4 & 37,4 & 0,0 \\
Set. & 1,9 & 26,9 & 0,0 \\
Out. & 4,2 & 2,6 & 85,4 \\
Nov. & 11,2 & 3,8 & 0,0 \\
Dez. & 23,7 & 53,9 & 96,3 \\
Total & 726,1 & 677,4 & 642,6 \\
\hline Fonte: AESA (2011) & & &
\end{tabular}

como Pilosocereus pentaedrophorus (facheiro), Cereus giganteus Engelm (mandacaru), Pilosocereus gounellei (xique-xique) e bromeliáceas, como a Bromelia laciniosa Mart exSchultez F. (macambira) e Bromelia karatas (banana-de-raposa).

Nessas áreas de Caatinga arbustiva arbórea aberta (T2), nas encostas dos morros e montanhas, registra-se a presença de uma vegetação densa, com poucos indivíduos herbáceos e cactáceos e maior frequência de indivíduos arbóreos, arbustos e árvores comuns em áreas classificadas como de Caatinga arbustiva arbórea fechada (T3).

São espécies como: Aspidosperma pyrifolium Mart (pereiro), Myracrodruon urundeuva (aroeira), Bauhinia forficata Linn (mororó), Tabebuia impertiginosa (pau d'arco), Combretum leprosum Mart (mufumbo), Cnidoscolus phyllacanthus (favela), Jatropha pohliana Muell Arg. (pinhão bravo), Croton sonderianus Muell. Arg. (marmeleiro), Caesalpinia ferrea Mart (jucá), Poincianella pyramidalis (Tul.) L. P. Queiroz, comb. nov. var. pyramidalis (catingueira), Piptadenia stipulaceae (Benth) (jurema branca), Mimosa tenuiflora (Willd) (jurema preta) e Anandenanthera columbrina (Vell) (angico), anteriormente citadas por Souza et al. (2007).

A Caatinga arbórea fechada (T4) ocorre nas encostas e topos das montanhas em áreas de difícil acesso, constituindo algumas poucas manchas.

$\mathrm{Na}$ análise dos índices de vegetação gerados verificou-se uma redução do NDVI do ano 2000 para o ano 2010, mesmo se analisando os parâmetros estatísticos das imagens IVDN_2000 e 2010 tendo-se registrado um crescimento da média de 2000 para 2010 (137,4 e 138,4 respectivamente) e da amplitude dos valores mínimos e máximos dos níveis de cinza (37 e 251, na imagem 2000 e 5 e 225 , na imagem 2010) entre as duas imagens (214 e 220, respectivamente).

As Figuras 2 e 3 representam a distribuição dos valores de NDVI e mostram predominância dos valores entre 0 e $0,1 \mathrm{em}$ cerca de 65\% da área da sub-bacia.

Os resultados sinalizam que as respostas obtidas pelo índice de vegetação indicam redução no NDVI do ano de 2000 para o ano de 2010, em grande parte influenciada pelas precipitações médias observadas na área que foram, em 2000, 677,4 mm e em 2010, 642,6 mm, reiterando ser o bioma Caatinga fortemente susceptível à presença ou ausência de chuvas (Santos \& Brito, 2007).

Durante os meses de julho, agosto e setembro de 2000, período anterior à data das imagens, as precipitações médias observadas foram mais elevadas do que as médias registradas em 2010 nesses meses sendo, inclusive, superiores às respectivas médias climatológicas mensais para a área. Considerando que na Caatinga há, quando submetida a períodos mais intensos de precipitações, incremento considerável da massa foliar influenciando sobremaneira no fluxo de energia eletromagnética refletida, justificada pela alta reflectância na banda 4 como resultado das precipitações registradas no ano 2000, nas porções noroeste, oeste, sul e sudeste da área. 


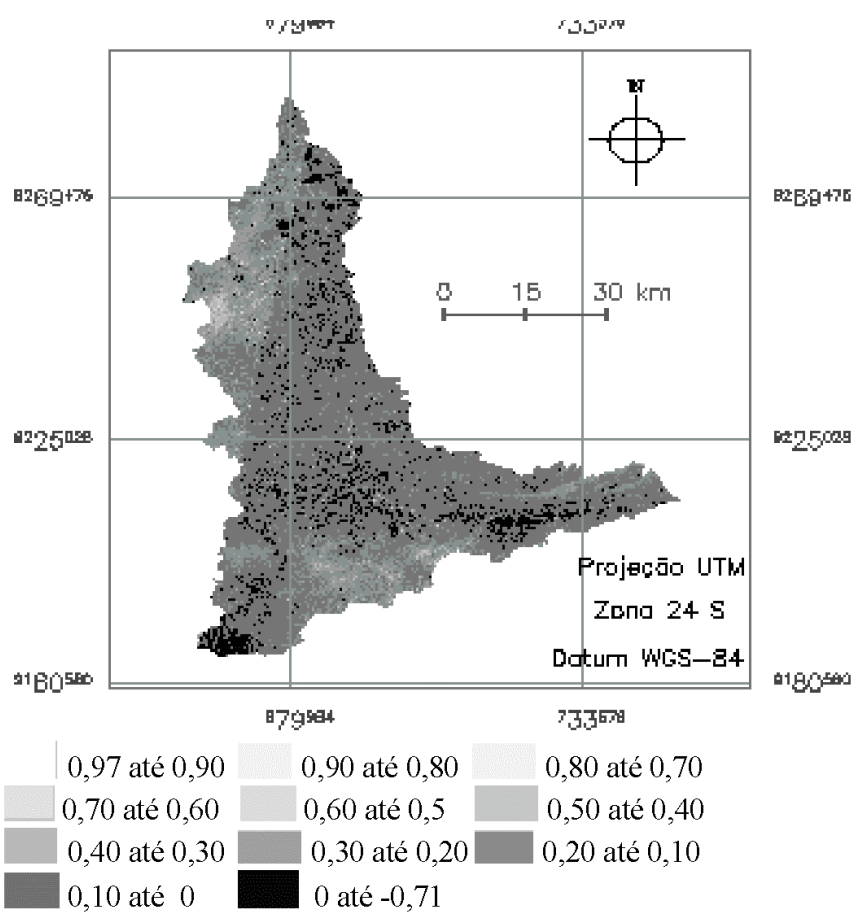

Figura 2. Sub-Bacia do Rio Espinharas: NDVI_2000 - Imagem classificada

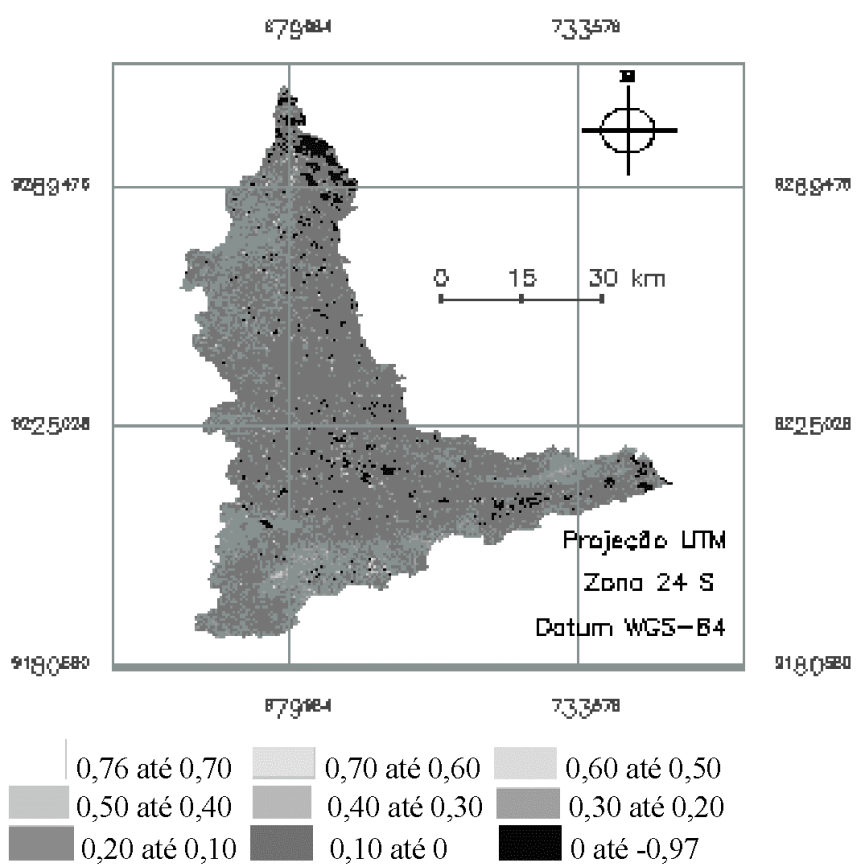

Figura 3. Sub-Bacia do Rio Espinharas: NDVI_2010 - Imagem classificada

A Figura 4 mostra a alteração da cobertura vegetal na área de estudo através da imagem diferença classificada considerando-se os valores da média $(\mu)$ de distribuição dos níveis de cinza na imagem e do desvio padrão $(\sigma)$, segundo os limiares $[0, \mu-\sigma]$, $[\mu-\sigma, \mu+\sigma]$ e $[\mu+\sigma, 254]$, correspondendo às classes temáticas: desmatamento/redução da cobertura vegetal $[0 ; 117,9114]$, com valores negativos entre - 127 e -10, 12,6\% da área; sem alteração $[117,9114 ; 138,2317]$, com valores próximos de zero ou iguais a zero, entre -10 e 11, 80\% da área e áreas de regeneração/

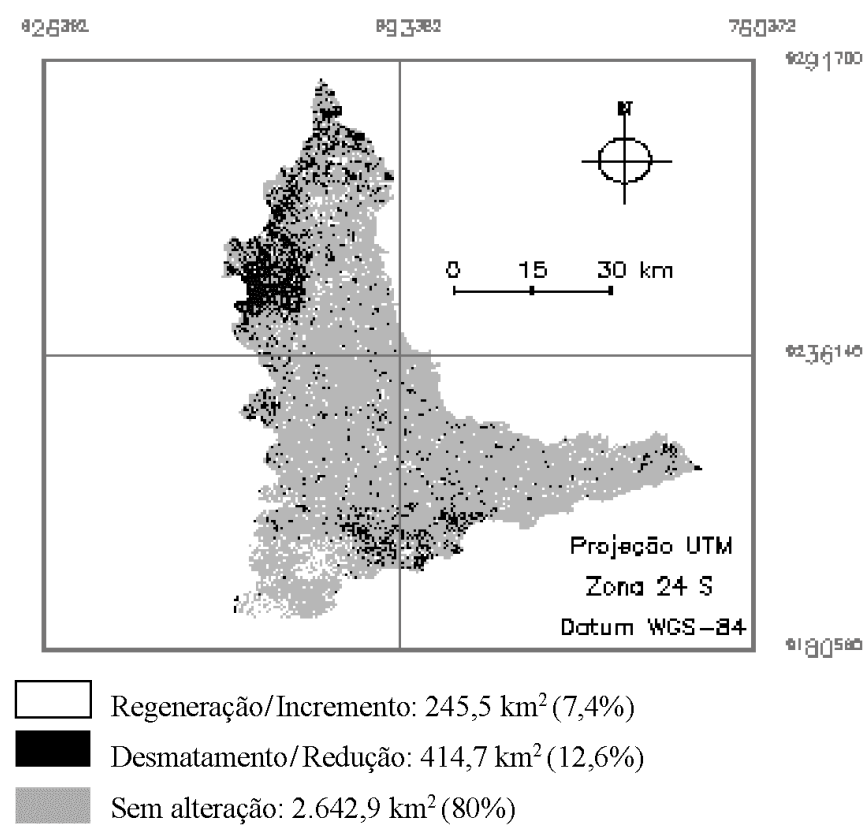

Figura 4. Sub-bacia do Rio Espinharas: Alteração da cobertura vegetal 2000-2010

incremento de vegetação [138,2317; 254], com valores positivos entre 11 e 127, 7,4\% da área.

A situação de que, na maior parte da área da sub-bacia em estudo, ou seja, $80 \%$ do total, não houve alteração da cobertura vegetal do ano 2000 para o ano de 2010 e sendo uma área de acentuado antropismo com trechos altamente degradados, revela-se como produto de um quadro de degradação há muito estabelecido.

O corte raso, realizado sucessivas vezes para obtenção de estacas, lenha e produção de carvão; a queima do material de desbaste como processo de preparação do solo para a agricultura de subsistência; a pecuária extensiva de bovinos a partir das últimas décadas do século XVII (Alves, 2007; Alves et al., 2008; Nogueira \& Simões, 2009), de caprinos e de ovinos; o esgotamento do solo pela prática da monocultura do algodão em extensas áreas, sobretudo a partir do século XIX até o final da década de 1970 e agora sem uso e outras formas de antropismo desencadearam tal degradação (Paraíba, 2011).

A própria topografia da área, de relevo plano, facilitou o acesso e o deslocamento de populações e rebanhos, a instalação de núcleos de povoamento originários de grandes fazendas de gado, ao longo dos leitos dos rios, e a exploração agrícola (Paraíba, 2011).

A diminuição progressiva de indivíduos arbóreos na área estudada ao longo do tempo tem provocado uma condição de pobreza crescente do banco de sementes, ausência de plântulas no solo da área e de partes vegetativas que possam originar novos indivíduos, a impossibilidade da disseminação de sementes através do vento por conta da retirada das árvores matrizes e a consequente exposição direta do solo à ação da erosão, impossibilitam uma mudança, em termos quantitativos e qualitativos, da vegetação nesta área, aliada às condições climáticas desfavoráveis (Alves et al., 2008; Costa et al., 2009). 
Como consequência dessas condições é comum a presença de extensas áreas de solo exposto e de uma formação do tipo arbustiva esparsa, com domínio da Herissantia crispa (L.) Briz. (malva branca), da Mimosa tenuiflora (Willd) (jurema preta), do Jatropha pohliana Muell Arg. (pinhão-bravo), do Cnidoscolus phyllacanthus (favela), da Aspidosperma pyrifolium Mart (pereiro) e do Croton sonderianus Muell. Arg (marmeleiro), fato também observado por Maracajá et al. (2003) e Andrade et al. (2005), em estudos realizados em trechos de Caatinga nos estados do Rio Grande do Norte e da Paraíba, e outras espécies do gênero Mimosa, além da presença da Bromelia laciniosa Martex Schultez F. (macambira), do Cereus giganteus Enelm (mandacaru) e do Pilosocereus gounellei (xique-xique).

Em alguns trechos ao longo das margens dos rios e riachos ocorrem Licania rigida

Benth (oiticicas), Tabebuia caraiba (Mart.) Bur. (craibeiras) e indivíduos de Copernicia prunifera (Miller) H.E. Moore (carnaúba), como asseveram Sousa et al. (2008), indicativos de antigas matas ciliares.

\section{Conclusões}

1. Predominam baixos valores de índices de vegetação por diferença normalizada (NDVI) entre 0 e 0,1 , em 65,1 e 66\% da área estudada, nos anos 2000 e 2010 respectivamente, indicativos de solos expostos ou vegetação rala.

2. Apesar da redução dos valores mínimos e máximos dos índices de vegetação por diferença normalizada (NDVI), do ano de 2000 para o ano de 2010, a maior parte da área estudada se manteve inalterada quanto à cobertura vegetal.

3. A redução dos valores de NDVI ocorreu em função dos fatores pluviométricos que no ano 2000 possibilitou uma resposta fisiológica da vegetação mais favorável do que no ano de 2010, como também em decorrência das práticas de corte raso da vegetação para produção de estacas, carvão, lenha para uso doméstico ou comercial e preparo da área para a agricultura.

4. A situação de não alteração da cobertura vegetal no período 2000/2010 na maior parte da Sub-bacia do Rio Espinharas em toda a sua extensão central, de relevo plano e suave ondulado, demonstra situação de permanência de alto grau de antropismo e degradação.

\section{Literatura Citada}

AESA - Agência Executiva de Gestão das Águas do Estado da Paraíba. SIGaesa-web. Mapa interativo, 2010a. <http://www. geo.aesa.pb.gov.br/>

AESA - Agência Executiva de Gestão das Águas do Estado da Paraíba. Relatório anual sobre a situação dos recursos hídricos no Estado da Paraíba: Ano hidrológico 2008-2009. AESA, 2010b. <http://www.aesa.pb.gov.br/relatorios /hidrologico/ arquivos/Relatorio_Anual_Hidrologico_2008_2009.pdf >. 3 Jun 2011.
AESA - Agência Executiva de Gestão das Águas do Estado da Paraíba.Climatologia média e precipitações médias mensais observadas na área da Sub-Bacia do Rio Espinharas nos anos 2000 e 2010. Dados fornecidos pelo Setor de Meteorologia. João Pessoa: AESA, 2011.

Albuquerque, F. J. A.; Pimentel Neto, J. G.; Galvíncio, J. D. Análise da cobertura da terra em função da precipitação mensal (janeiro e outubro de 2006) utilizando imagens CBERS para o município de Ouricuri, PE. Revista de Geografia, v.24, p.6-18, 2007.

Alves, J. J. A. Geoecologia da caatinga no semi-árido do nordeste brasileiro. Revista Climatologia e Estudos da Paisagem, v.2, p.58-71, 2007.

Alves, J. J. A.; Araújo, M. A.; Nascimento, S. S. Degradação da caatinga: Uma investigação ecogeográfica. Revista Caminhos de Geografia, v.9, p.143-155,2008.

Andrade, L. A.; Pereira, I. M.; Leite, U. T.; Barbosa, M. R. V. Análise da cobertura de duas fitofisionomias de caatinga, com diferentes históricos de uso, no município de São João do Cariri, Estado da Paraíba. Cerne, v.11, p.253262,2005 .

Aquino, C. M. S.; Oliveira, J. G. B. Estudo da dinâmica do índice de vegetação por diferença normalizada (NDVI) no núcleo de São Raimundo Nonato-PI. Revista Espaço e Tempo, v.31, p.157-168, 2012.

Brasileiro, R. S. Alternativas de desenvolvimento sustentável no semiárido nordestino: Da degradação à conservação. Scientia Plena, v.5, p.1-12, 2009.

Camara, G.; Souza, R. C. M.; Freitas, U. M.; Garrido, J. SPRING: Integrating remote sensingand GIS by objectoriented data modelling. Computers \& Graphics, v.20, p.395-403, 1996.

Cavalcante, M. B. Ecoturismo no bioma Caatinga: O caso do Parque Estadual da Pedra da Boca, Paraíba. Revista Nordestina de Ecoturismo, v.2, p.25-38, 2009.

Costa, T. C. C.; Oliveira, M. A. J.; Accioly, L. J. O.; Silva, F. H. B. B. Análise da degradação da caatinga no núcleo de desertificação do Seridó (RN/PB). Revista Brasileira de Engenharia Agrícola e Ambiental, v.13, p.961-974, 2009.

Ferreira, C. G. T.; Oliveira, R. C.; Valls, J. F. M.; Loiola, M. I. B. Poaceae da Estação Ecológica do Seridó, Rio Grande do Norte, Brasil. Revista Hoehnea, v.4, p.679-707, 2009.

Firmino, J. L. N.; Lima, E. A.; Gomes Filho, M. F.; Araújo, P. C. Identificação de impactos ambientais através da análise comparativa do índice de vegetação derivado do satélite landsat-5 para a cidade de São João do rio do Peixe na Paraíba com a precipitação. Revista Verde de Agroecologia e Desenvolvimento Sustentável, v.4, p.17-22, 2009.

Franco, E. S.; Lira, V. M.; Farias, M. S. S.; Pordeus, R. V.; Lima, V. L. A. de. Uso de imagens TM/LANDSAT-5 na identificação da degradação ambiental na microbacia hidrográfica em Boqueirão - PB. Campo-território: Revista de Geografia Agrária, v.2, p.79-88, 2007. 
IBGE - Instituto Brasileiro de Geografia e Estatística. Censo, 2010. <http://www.ibge.gov.br/cidadesat/topwindow. htm?1>. 20 Abr. 2011.

Lacerda, A. V.; Barbosa, F. M.; Barbosa, M. R. V. Estudo do componente arbustivo-arbóreo de matas ciliares na bacia do rio Taperoá, semi-árido paraibano: uma perspectiva para a sustentabilidade dos recursos naturais. Oecologia Brasiliensis - Ecologia da Caatinga, v.11, p.331-340, 2007.

Maracajá, P. B.; Batista, C. H. F.; Sousa, A. H.; Vasconcelos, W. E. Levantamento florístico e fitosociológico do extrato arbustivo- arbóreo de dois ambientes na VilaSanta Catarina, Serra do Mel, RN. Revista de Biologia e Ciências da Terra, v.3, p.1-13, 2003.

Medeiros, Y. D. P. Análise dos impactos das mudanças climáticas em região semi-árida. Revista Brasileira de Recursos Hídricos, v.8, p.127-136, 2003.

Melo Filho, J. F.; Souza, A. L. V. O manejo e a conservação do solo no semi-árido baiano: Desafios para a sustentabilidade. Revista Bahia Agrícola, v.7, p.50-60, 2006.

Nogueira, F. R. B.; Simões, S. V. D. Uma abordagem sistêmica para a agropecuária e a dinâmica evolutiva dos sistemas de produção no nordeste semi-árido. Revista Caatinga, v.22, p.1-6,2009.

Paraíba. Secretaria de Estado da Ciência e Tecnologia e do Meio Ambiente - SECTMA. PERH-PB: Plano estadual de recursos hídricos: Resumo executivo \& atlas/Governo do Estado da Paraíba; Secretaria de Estado da Ciência e Tecnologia e do Meio Ambiente, SECTMA; Agência Executiva de Gestão de Águas do Estado da Paraíba, Brasília: Consórcio TC/ BR - Concremat, 2006. 112p.
Paraíba. Programa de ação estadual de combate à desertificação e mitigação dos efeitos da seca no estado da Paraíba: PAE-PB. João Pessoa: Secretaria de Estado dos Recursos Hídricos, do Meio Ambiente e da Ciência e Tecnologia. Superintendência de Administração do Meio Ambiente, 2011. 137p.

Pessoa, M. F.; Guerra, A. M. N. M.; Maracajá, P. B.; Lira, J. F. B.; Diniz Filho, E. T. Estudo da cobertura vegetal em ambientes da caatinga com diferentes formas de manejo no assentamento Moacir Lucena, Apodi - RN. Revista Caatinga, v.21, p.40-48, 2008.

Ramalho Filho, A.; Beek, K. J. Sistema de avaliação da aptidão agrícola das terras. 3.ed. Rio de Janeiro: Embrapa CNPS, 1995. 65p.

Santos, A. R.; Peluzio, T. M. O.; Saito, N. S. Spring 5.1.2: Passo a passo: Aplicações práticas. Alegre: CAUFES, 2010. 153p.

Santos, C. A. C.; Brito, J. I. B. Análise dos índices de extremos para o semiárido do Brasil e suas relações com TSM e IVDN. Revista Brasileira de Meteorologia, v.22, p.303-312, 2007.

Sousa, R. F.; Barbosa, M. P.; Sousa Júnior, S. P.; Nery, A. R.; Lima, A. N. Estudo da evolução espaço-temporal da cobertura vegetal do município de Boa Vista-PB, utilizando geoprocessamento. Revista Caatinga, v.21, p.22-30,2008.

Souza, P. F.; Lima, J. R.; Arruda, P. M.; Mendonça, I. F.C.; Silva, J. A.; Nóbrega, A. M. F. Estimativa do nível de cobertura dos solos e levantamento dos remanescentes arbóreos na bacia hidrográfica do açude Jatobá, PB. Revista Pesquisa, v.1, p.129-135,2007.

SUDEMA - Superintendência de Administração do Meio Ambiente. Atualização do diagnóstico florestal do Estado da Paraíba. João Pessoa: SUDEMA, 2004. 268p. 